
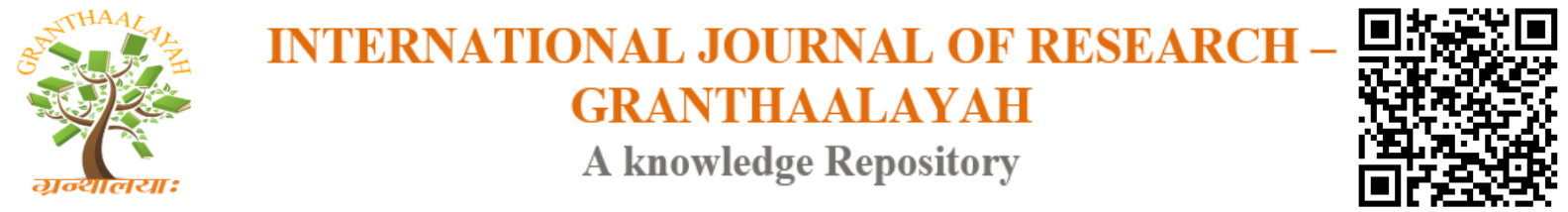

Science

\title{
GREEN DARNER ALGORITHM FOR SOLVING OPTIMAL POWER FLOW PROBLEM
}

\author{
Dr.K.Lenin ${ }^{* 1}$ \\ ${ }^{* 1}$ Department of EEE Prasad V.Potluri Siddhartha Institute of Technology, Kanuru, Vijayawada, \\ Andhra Pradesh, India
}

\begin{abstract}
In this paper a Green Darner (GD) algorithm is used to solve optimal reactive power problem. The key inducement of the Green Darner (GD) algorithm initiated from inert and vibrant swarming behaviors. These two swarming behaviours are very similar to the two key segment of optimization using meta-heuristics: exploration and exploitation. Green Darner (GD) engenders sub swarms and flies over assorted areas in an inert swarm, \& it will be the main goal of the exploration segment. In the inert swarm, conversely, Green Darner (GD) flies in bigger swarms and down to one direction, which is constructive in the exploitation segment. In this proposed Green Darner (GD) algorithm, two necessary segments of optimization, exploration and exploitation, are planned by modeling the social communication of Green Darner (GD) in navigating, probing for foods, and keep away from enemies when swarming vigorously or statistically. The projected Green Darner (GD) algorithm has been tested in standard IEEE 118 \& practical 191 bus test systems and simulation results show clearly about the improved performance of the projected Green Darner (GD) algorithm in reducing the real power loss.
\end{abstract}

Keywords: Green Darner; Optimization; Optimal Reactive Power; and Transmission Loss.

Cite This Article: Dr.K.Lenin. (2017). "GREEN DARNER ALGORITHM FOR SOLVING OPTIMAL POWER FLOW PROBLEM." International Journal of Research Granthaalayah, 5(9), 106-115. https://doi.org/10.29121/granthaalayah.v5.i9.2017.2210.

\section{Introduction}

Many algorithms are employed to solve the Reactive Power problem. Dissimilar types of arithmetical methods like the gradient method [1-2], Newton method [3] and linear programming [4-7] have been previously used to solve the optimal reactive power problem. The voltage stability problem plays a central role in power system planning and operation [8].Evolutionary algorithms such as genetic algorithm, Hybrid differential evolution algorithm, Biogeography Based algorithm, a fuzzy based approach, an improved evolutionary programming [9-15] have been already utilized to solve the reactive power flow problem In [16-18] different methodologies are effectively handled the optimal power problem. In [19-20], a programming based approach and probabilistic algorithm is used to solve the optimal reactive power problem. 
This paper proposes Green Darner (GD) algorithm to solve reactive power dispatch problem. Green Darner is small predators that hound almost all other petite insects in environment. Fairy Green Darner also predate on other insects. The attractive fact about Green Darner is their elite and an archetypal swarming behaviour. Green Darner swarm for only two reasons: hunting and migration. The previous is called static swarm, and the second is called dynamic swarm. In static swarm, Green Darner produces small groups and flies back and forth over a minute area to hunt other flying preys such as butterflies and mosquitoes [21-24]. Restricted movements and fast changes in the flying path are the main characteristics of a static swarm. In pulsating swarms, conversely, an massive number of Green Darner make the swarm for migrating in one direction over stretched distances. The main inspiration of the Green Darner (GD) algorithm initiate from static and dynamic swarming behaviours. These two swarming behaviours are very similar to the two key segments of optimization using meta-heuristics: exploration and exploitation. Green Darner produces sub-swarms and flies over diverse regions in a static swarm, which is the main objective of the exploration segment. In the static swarm, however, Green Darner flies in bigger swarms and along one direction, which is productive in the exploitation segment. The proposed Green Darner (GD) algorithm has been evaluated in IEEE 118 \& practical 191 bus test systems. The simulation results show about the planned approach outperforms all the entitled reported algorithms in minimization of real power loss.

\section{Problem Formulation}

The optimal power flow problem is treated as a general minimization problem with constraints, and can be mathematically written in the following form:

Minimize $f(x, u)$

subject to $g(x, u)=0$

and

$\mathrm{h}(\mathrm{x}, \mathrm{u}) \leq 0$

where $f(x, u)$ is the objective function. $g(x . u)$ and $h(x, u)$ are respectively the set of equality and inequality constraints. $x$ is the vector of state variables, and $u$ is the vector of control variables. The state variables are the load buses (PQ buses) voltages, angles, the generator reactive powers and the slack active generator power:

$\mathrm{x}=\left(\mathrm{P}_{\mathrm{g} 1}, \theta_{2}, \ldots, \theta_{\mathrm{N}}, \mathrm{V}_{\mathrm{L} 1}, ., \mathrm{V}_{\mathrm{LNL}}, \mathrm{Q}_{\mathrm{g} 1}, \ldots, \mathrm{Q}_{\mathrm{gng}}\right)^{\mathrm{T}}$

The control variables are the generator bus voltages, the shunt capacitors/reactors and the transformers tap-settings:

$\mathrm{u}=\left(\mathrm{V}_{\mathrm{g}}, \mathrm{T}, \mathrm{Q}_{\mathrm{c}}\right)^{\mathrm{T}}$

or

$\mathrm{u}=\left(\mathrm{V}_{\mathrm{g} 1}, \ldots, \mathrm{V}_{\mathrm{gng}}, \mathrm{T}_{1}, \ldots, \mathrm{T}_{\mathrm{Nt}}, \mathrm{Q}_{\mathrm{c} 1}, \ldots, \mathrm{Q}_{\mathrm{cNc}}\right)^{\mathrm{T}}$

Where ng, nt and nc are the number of generators, number of tap transformers and the number of shunt compensators respectively. 


\section{Objective Function}

\subsection{Active Power Loss}

The objective of the reactive power dispatch is to minimize the active power loss in the transmission network, which can be described as follows:

$F=P L=\sum_{k \in N b r} g_{k}\left(V_{i}^{2}+V_{j}^{2}-2 V_{i} V_{j} \cos \theta_{i j}\right)$

or

$F=P L=\sum_{i \in N g} P_{g i}-P_{d}=P_{g s l a c k}+\sum_{i \neq s l a c k}^{N g} P_{g i}-P_{d}$

where $g_{k}$ : is the conductance of branch between nodes $i$ and $j$, Nbr: is the total number of transmission lines in power systems. $\mathrm{P}_{\mathrm{d}}$ : is the total active power demand, $\mathrm{P}_{\text {gi }}$ : is the generator active power of unit $i$, and $\mathrm{P}_{\text {gsalck: }}$ is the generator active power of slack bus.

\subsection{Voltage Profile Improvement}

For minimizing the voltage deviation in PQ buses, the objective function becomes:

$F=P L+\omega_{v} \times V D$

where $\omega_{\mathrm{v}}$ : is a weighting factor of voltage deviation.

VD is the voltage deviation given by:

$V D=\sum_{i=1}^{N p q}\left|V_{i}-1\right|$

\subsection{Equality Constraint}

The equality constraint $\mathrm{g}(\mathrm{x}, \mathrm{u})$ of the ORPD problem is represented by the power balance equation, where the total power generation must cover the total power demand and the power losses:

$P_{G}=P_{D}+P_{L}$

This equation is solved by running Newton Raphson load flow method, by calculating the active power of slack bus to determine active power loss.

\subsection{Inequality Constraints}

The inequality constraints $\mathrm{h}(\mathrm{x}, \mathrm{u})$ reflect the limits on components in the power system as well as the limits created to ensure system security. Upper and lower bounds on the active power of slack bus, and reactive power of generators:

$P_{\text {gslack }}^{\min } \leq P_{\text {gslack }} \leq P_{\text {gslack }}^{\max }$ 
$Q_{g i}^{\min } \leq Q_{g i} \leq Q_{g i}^{\max }, i \in N_{g}$

Upper and lower bounds on the bus voltage magnitudes:

$V_{i}^{\min } \leq V_{i} \leq V_{i}^{\max }, i \in N$

Upper and lower bounds on the transformers tap ratios:

$T_{i}^{\min } \leq T_{i} \leq T_{i}^{\max }, i \in N_{T}$

Upper and lower bounds on the compensators reactive powers:

$Q_{c}^{\min } \leq Q_{c} \leq Q_{C}^{\max }, i \in N_{C}$

Where $\mathrm{N}$ is the total number of buses, $\mathrm{N}_{\mathrm{T}}$ is the total number of Transformers; $\mathrm{N}_{\mathrm{c}}$ is the total number of shunt reactive compensators.

\section{Green Darner (GD) algorithm}

According to Reynolds [25], the behaviour of swarms tracks on three primitive principles: partition- refers to the static collision evasion of the individuals from other individuals in the neighbourhood. Alliance - indicates velocity matching of individuals to that of other individuals in neighbourhood. Pulling together - refers to the inclination of individuals towards the centre of the mass of the neighbourhood.The key objective of any swarm is survival, so all of the individuals should be fascinated towards food sources and sidetracked outward enemies. The behaviours are scientifically modelled as follows: The partition is calculated as follows,

$T_{i}=-\sum_{j=1}^{N} R-R_{j}$

Where $\mathrm{Z}$ is the position of the current individual, $\mathrm{R}_{\mathrm{j}}$ shows the position $\mathrm{j}$-th neighboring individual, and $\mathrm{N}$ is the number of neighbouring individuals.

Alliance is calculated as follows:

$M_{i}=\frac{\sum_{j=1}^{N} M_{j}}{N}$

Where $\mathrm{M}_{\mathrm{j}}$ shows the velocity of $\mathrm{j}$-th neighboring individual.

The cohesion is calculated as follows:

$K_{i}=\frac{\sum_{j=1}^{N} R_{j}}{N}-R$

Where $\mathrm{R}$ is the position of the current individual, $\mathrm{N}$ is the number of neighbourhoods, and $\mathrm{R}_{\mathrm{j}}$ shows the position $\mathrm{j}$-th neighbouring individual. 
Pulling together towards a food source is calculated as follows:

$\mathrm{B}_{\mathrm{i}}=\mathrm{R}^{+}-\mathrm{R}$

Where $\mathrm{R}$ is the position of the current individual, and $\mathrm{R}^{+}$shows the position of the food source.

Diversion outwards an enemy is calculated as follows:

$F_{i}=R^{-}+R$

Where $\mathrm{R}$ is the position of the existing individual, and $\mathrm{R}^{-}$shows the location of the enemy.

To modernize the location of artificial Green Darner in an exploration space and imitate their movements, two vectors are considered: step $(\Delta R)$ and position $(\mathrm{R})$. The step vector is analogous to the velocity vector in Particle swarm optimization (PSO), and the Green Darner (GD) algorithm is developed based on the framework of the PSO algorithm. The step vector can be defined as follows,

$\Delta R_{t+1}=\left(t T_{i}+m M_{i}+k K_{i}+b B_{i}+\mathrm{f} F_{i}\right)+w \Delta R_{t}$

where $d$ shows the separation weight, $T_{i}$ indicates the division of the $\mathrm{i}$-th individual, $\mathrm{m}$ is the alliance weight, $M_{i}$ is the position of $i$-th individual, $k$ indicates the cohesion weight, $K_{i}$ is the cohesion of the $i$-th individual, $b$ is the food factor, $e_{i}$ is the food source of the $i$-th individual, $f$ is the enemy factor, $F_{i}$ is the location of enemy of the $\mathrm{i}$-th individual, $\mathrm{w}$ is the inertia weight, and $\mathrm{t}$ is the iteration counter.

Later than calculating the step vector, the position vectors are designed as follows:

$\mathrm{R}_{\mathrm{t}+1}=\mathrm{R}_{\mathrm{t}}+\Delta \mathrm{R}_{\mathrm{t}+1}$

Where $t$ is the current iteration.

In a static swarm, however, alignments are very low while cohesion is high to assail preys. Consequently, we assign Green Darner with high alignment and low cohesion weights when discover the exploration space and little alignment and high cohesion when exploit the exploration space. For alteration between exploration and exploitation, the radii of neighbourhood are amplified relative to the number of iterations. An additional way to balance exploration and exploitation is to adaptively adjust the swarming factors $(\mathrm{t}, \mathrm{m}, \mathrm{k}, \mathrm{b}, \mathrm{f}$, and $\mathrm{w}$ ) throughout optimization.

To perk up the arbitrariness, stochastic behaviour, and exploration of the artificial Green Darner, they are requisite to fly around the explore space using an arbitrary walk (Levy flight) when there is no neighbouring solutions. In this case, the location of Green Darner is modernized using the following equation:

$R_{t+1}=R_{t}+\operatorname{Levy}(x) \times R_{t}$ 
Where $\mathrm{t}$ is the current iteration and $\mathrm{x}$ is the dimension of the position vectors.

The Levy flight is calculated as follows

Levy flight [26] is a rank of non-Gaussian random processes whose arbitrary walks are drawn from Levy stable distribution. This allocation is a simple power-law formula $L(s) \sim|s|^{-1-\beta}$ where 0 $<\beta<2$ is an index. Mathematically exclamation, an easy version of Levy distribution can be defined as :

$L(s, \gamma, \mu)=\left\{\begin{array}{c}\sqrt{\frac{\gamma}{2 \pi}} \\ 0 \quad \text { if } s \leq 0\end{array}\right.$ exp $\left[-\frac{\gamma}{2(s-\mu)}\right] \frac{1}{(s-\mu)^{3 / 2}} \quad$ if $0<\mu<s<\infty$

Where $\gamma>0$ parameter is scale (controls the scale ofdistribution) parameter, $\mu$ parameter is location or shift parameter. In general, Levy distribution should be defined in terms of Fourier transform

$F(k)=\exp \left[-\alpha|k|^{\beta}\right], 0<\beta \leq 2$,

Where $\alpha$ is a parameter within [-1,1] interval and known as scale factor. An index of o stability $\beta$ $\in[0,2]$ is also referred to as Levy index. In particular, for $\beta=1$, the integral can be carried out analytically and is known as the Cauchy probability distribution. One more special case when $\beta=$ 2 , the distribution correspond to Gaussian distribution. $\beta$ and $\alpha$ parameters take a key part in determination of the distribution. The parameter $\beta$ controls the silhouette of the probability distribution in such a way that one can acquire different shapes of probability distribution, especially in the tail region depending on the parameter $\beta$. Thus, the smaller $\beta$ parameter causes the distribution to make longer jumps since there will be longer tail. It makes longer jumps for smaller values whereas it makes shorter jumps for bigger values.

The Green Darner (GD) algorithm starts optimization process by generating a set of arbitrary solutions for a given optimization problems. In fact, the position and step vectors of Green Darner are initialized by random values defined within the lower and upper bounds of the variables. In each iteration, the position and step of each Green Darner are updated using Eqs.(22-24).For modernizing $\mathrm{R}$ and $\Delta R$ vectors, neighbourhood of each Green Darner is chosen by calculating the Euclidean distance between all the Green Darner and selecting $\mathrm{N}$ of them. The position modernizing process is sustained iteratively until the end criterion is satisfied.

Initialize the Green Darner population $\mathrm{R}_{\mathrm{i}}(\mathrm{i}=1,2, \ldots, \mathrm{n})$

Initialize step vectors $\Delta \mathrm{R}_{\mathrm{i}}(\mathrm{i}=1,2, \ldots, \mathrm{n})$

While the end condition is not satisfied

Compute the objective values of all Green Darner

Modernize the food source and enemy

Update factors ( $\mathrm{t}, \mathrm{m}, \mathrm{k}, \mathrm{b}, \mathrm{f}$, and $\mathrm{w}$ )

Compute T, M, K, B, and F using Eqs. (17-18)

Update neighbouring radius if a Green Darner has at least one neighbouring Green Darner Update velocity vector using Eq. (22)

Update position vector using Eq. (23)

Else 
Update position vector using Eq. (24)

End if

Make sure and adjust the novel positions based on the boundaries of variables

End while

\section{Simulation Results}

At first Green Darner (GD) algorithm has been tested in standard IEEE 118-bus test system [27]. The system has 54 generator buses, 64 load buses, 186 branches and 9 of them are with the tap setting transformers. The limits of voltage on generator buses are $0.95-1.1$ per-unit., and on load buses are $0.95-1.05$ per-unit. The limit of transformer rate is $0.9-1.1$, with the changes step of 0.025 . The limitations of reactive power source are listed in Table 1, with the change in step of 0.01 .

Table 1: Limitation of reactive power sources

\begin{tabular}{|l|l|l|l|l|l|l|l|}
\hline BUS & 5 & 34 & 37 & 44 & 45 & 46 & 48 \\
\hline QCMAX & 0 & 14 & 0 & 10 & 10 & 10 & 15 \\
\hline QCMIN & -40 & 0 & -25 & 0 & 0 & 0 & 0 \\
\hline BUS & 74 & 79 & 82 & 83 & 105 & 107 & 110 \\
\hline QCMAX & 12 & 20 & 20 & 10 & 20 & 6 & 6 \\
\hline QCMIN & 0 & 0 & 0 & 0 & 0 & 0 & 0 \\
\hline
\end{tabular}

The statistical comparison results of 50 trial runs have been list in Table 2 and the results clearly show the better performance of proposed Green Darner (GD) algorithm.

Table 2: Comparison results

\begin{tabular}{|l|l|l|l|l|}
\hline Active power loss (p.u) & $\begin{array}{l}\text { BBO } \\
{[\mathbf{2 8}]}\end{array}$ & $\begin{array}{l}\text { ILSBBO/ } \\
\text { strategy1 } \\
{[\mathbf{2 8}]}\end{array}$ & $\begin{array}{l}\text { ILSBBO/ } \\
\text { strategy1 } \\
{[\mathbf{2 8}]}\end{array}$ & $\begin{array}{l}\text { Proposed } \\
\text { GD }\end{array}$ \\
\hline Min & 128.77 & 126.98 & 124.78 & 115.06 \\
\hline Max & 132.64 & 137.34 & 132.39 & 119.24 \\
\hline Average & 130.21 & 130.37 & 129.22 & 116.82 \\
\hline
\end{tabular}

Then the Green Darner (GD) algorithm has been tested in practical 191 test system and the following results have been obtained. In Practical 191 test bus system - Number of Generators $=$ 20 , Number of lines $=200$, Number of buses $=191$ Number of transmission lines $=55$. Table 3 shows the optimal control values of practical 191 test system obtained by GD method. And table 4 shows the results about the value of the real power loss by obtained by Green Darner (GD) algorithm.

Table 3. Optimal Control values of Practical 191 utility (Indian) system by GD method

\begin{tabular}{l|l|l|l|l}
\hline VG1 & 1.10 & \multirow{5}{*}{ VG 11 } & 0.90 \\
VG 2 & 0.72 & VG 12 & 1.00 \\
\hline VG 3 & 1.01 & VG 13 & 1.00 \\
\hline VG 4 & 1.01 & VG 14 & 0.90 \\
\hline VG 5 & 1.10 & VG 15 & 1.00 \\
\hline
\end{tabular}




\begin{tabular}{l|l|l|l|l}
\hline VG 6 & 1.10 & \multirow{4}{*}{} & VG 16 & 1.00 \\
VG 7 & 1.10 & VG 17 & 0.90 \\
VG 8 & 1.01 & VG 18 & 1.00 \\
VG 9 & 1.10 & VG 19 & 1.10 \\
\cline { 1 - 1 } VG 10 & 1.01 & VG 20 & 1.10 \\
\hline
\end{tabular}

\begin{tabular}{|c|c|c|c|c|c|}
\hline $\mathrm{T} 1$ & 1.00 & $\mathrm{~T} 21$ & 0.90 & $\mathrm{~T} 41$ & 0.90 \\
\hline $\mathrm{T} 2$ & 1.00 & T22 & 0.90 & T42 & 0.90 \\
\hline T3 & 1.00 & T23 & 0.90 & T43 & 0.91 \\
\hline $\mathrm{T} 4$ & 1.10 & T24 & 0.90 & T44 & 0.91 \\
\hline T5 & 1.00 & $\mathrm{~T} 25$ & 0.90 & T45 & 0.91 \\
\hline T6 & 1.00 & T26 & 1.00 & T46 & 0.90 \\
\hline $\mathrm{T} 7$ & 1.00 & T27 & 0.90 & T47 & 0.91 \\
\hline $\mathrm{T} 8$ & 1.01 & T28 & 0.90 & T48 & 1.00 \\
\hline T9 & 1.00 & T29 & 1.01 & T49 & 0.90 \\
\hline T10 & 1.00 & T30 & 0.90 & T50 & 0.90 \\
\hline T11 & 0.90 & T31 & 0.90 & T51 & 0.90 \\
\hline $\mathrm{T} 12$ & 1.00 & T32 & 0.90 & T52 & 0.90 \\
\hline $\mathrm{T} 13$ & 1.01 & T33 & 1.01 & T53 & 1.00 \\
\hline T14 & 1.01 & T34 & 0.90 & T54 & 0.90 \\
\hline $\mathrm{T} 15$ & 1.01 & T35 & 0.90 & T55 & 0.90 \\
\hline T19 & 1.02 & T39 & 0.90 & & \\
\hline $\mathrm{T} 20$ & 1.01 & T40 & 0.90 & & \\
\hline
\end{tabular}

Table 4: Optimum real power loss values obtained for practical 191 utility (Indian) system by GD method.

\begin{tabular}{l|l}
\hline Real power Loss (MW) & GD \\
\hline Min & 143.182 \\
\hline Max & 147.164 \\
\hline Average & 144.062 \\
\hline
\end{tabular}

\section{Conclusion}

In this paper, Green Darner (GD) algorithm has been efficiently solved the Optimal Reactive Power problem. The projected algorithm has been tested in standard IEEE 118 \& practical 191 bus test systems. Simulation study shows the heftiness of projected Green Darner (GD) algorithm in providing better optimal solution by decreasing the real power loss. The control variables values obtained after the optimization are well within the limits.

\section{References}

[1] O.Alsac,and B. Scott, "Optimal load flow with steady state security", IEEE Transaction. PAS 1973, pp. 745-751.

[2] Lee K Y, Paru Y M, Oritz J L -A united approach to optimal real and reactive power dispatch , IEEE Transactions on power Apparatus and systems 1985: PAS-104 : 1147-1153 
[3] A.Monticelli , M .V.F Pereira , and S. Granville, "Security constrained optimal power flow with post contingency corrective rescheduling", IEEE Transactions on Power Systems :PWRS-2, No. 1, pp.175-182.,1987.

[4] DeebN ,Shahidehpur S.M ,Linear reactive power optimization in a large power network using the decomposition approach. IEEE Transactions on power system 1990: 5(2) : 428-435

[5] E. Hobson ,'Network consrained reactive power control using linear programming, ' IEEE Transactions on power systems PAS -99 (4) ,pp 868=877, 1980

[6] K.Y Lee, Y.M Park, and J.L Oritz, "Fuel -cost optimization for both real and reactive power dispatches", IEE Proc; 131C,(3), pp.85-93.1992.

[7] M.K. Mangoli, and K.Y. Lee, "Optimal real and reactive power control using linear programming”, Electr.PowerSyst.Res, Vol.26, pp.1-10,1993.

[8] C.A. Canizares , A.C.Z.de Souza and V.H. Quintana , "Comparison of performance indices for detection of proximity to voltage collapse ," vol. 11. no.3, pp.1441-1450, Aug 1996.

[9] K.Anburaja, "Optimal power flow using refined genetic algorithm", Electr.PowerCompon.Syst, Vol. 30, 1055-1063, 2002.

[10] D. Devaraj, and B. Yeganarayana, "Genetic algorithm based optimal power flow for security enhancement", IEE proc-Generation.Transmission and. Distribution; 152, 6 November 2005.

[11] A. Berizzi, C. Bovo, M. Merlo, and M. Delfanti, "A ga approach to compare orpf objective functions including secondary voltage regulation," Electric Power Systems Research, vol. 84, no. 1, pp. $187-194,2012$.

[12] C.-F. Yang, G. G. Lai, C.-H.Lee, C.-T. Su, and G. W. Chang, "Optimal setting of reactive compensation devices with an improved voltage stability index for voltage stability enhancement," International Journal of Electrical Power and Energy Systems, vol. 37, no. 1, pp. $50-57,2012$.

[13] P. Roy, S. Ghoshal, and S. Thakur, "Optimal var control for improvements in voltage profiles and for real power loss minimization using biogeography based optimization," International Journal of Electrical Power and Energy Systems, vol. 43, no. 1, pp. 830 - 838, 2012.

[14] B. Venkatesh, G. Sadasivam, and M. Khan, "A new optimal reactive power scheduling method for loss minimization and voltage stability margin maximization using successive multi-objective fuzzy lp technique," IEEE Transactions on Power Systems, vol. 15, no. 2, pp. 844 - 851, may 2000 .

[15] W. Yan, S. Lu, and D. Yu, "A novel optimal reactive power dispatch method based on an improved hybrid evolutionary programming technique," IEEE Transactions on Power Systems, vol. 19, no. 2, pp. 913 - 918, may 2004.

[16] W. Yan, F. Liu, C. Chung, and K. Wong, "A hybrid genetic algorithminterior point method for optimal reactive power flow," IEEE Transactions on Power Systems, vol. 21, no. 3, pp. 1163 1169, aug. 2006.

[17] J. Yu, W. Yan, W. Li, C. Chung, and K. Wong, "An unfixed piecewiseoptimal reactive powerflow model and its algorithm for ac-dc systems," IEEE Transactions on Power Systems, vol. 23, no. 1 , pp. $170-176$, feb. 2008.

[18] F. Capitanescu, "Assessing reactive power reserves with respect to operating constraints and voltage stability," IEEE Transactions on Power Systems, vol. 26, no. 4, pp. 2224-2234, nov. 2011.

[19] Z. Hu, X. Wang, and G. Taylor, "Stochastic optimal reactive power dispatch: Formulation and solution method," International Journal of Electrical Power and Energy Systems, vol. 32, no. 6, pp. $615-621,2010$.

[20] A. Kargarian, M. Raoofat, and M. Mohammadi, "Probabilistic reactive power procurement in hybrid electricity markets with uncertain loads," Electric Power Systems Research, vol. 82, no. 1, pp. 68 - 80, 2012.

[21] Thorp JH, Rogers DC (2014) Thorp and Covich's freshwater invertebrates: ecology and general biology. Elsevier, Amsterdam 
[22] Wikelski M, Moskowitz D, Adelman JS, Cochran J, Wilcove DS, May ML (2006) Simple rules guide dragonfly migration. Biol Lett 2:325-329

[23] Russell RW, May ML, Soltesz KL, Fitzpatrick JW (1998) Massive swarm migrations of dragonflies (Odonata) in eastern North America. AmMidl Nat 140:325-342.

[24] S. Mirjalili, "Dragonfly Algorithm: A New Meta-heuristic Optimization Technique for Solving Single-objective, Discrete, and Multi-objective Problems", Neural Computing and Applications, in press, 2015.

[25] Reynolds CW (1987) Flocks, herds and schools: a distributed behavioral model. ACM SIGGRAPH Comput Gr 21:25-34.

[26] HüseyinHakli and Harun Uğuz, "Levy Flight Distribution for Scout Bee in Artificial Bee Colony Algorithm" Lecture Notes on Software Engineering, Vol. 1, No. 3, August 2013.

[27] IEEE, "The IEEE 30-bus test system and the IEEE 118-test system", (1993), http://www.ee.washington.edu/trsearch/pstca/.

[28] Jiangtao Cao, Fuli Wang and Ping Li, "An Improved Biogeography-based Optimization Algorithm for Optimal Reactive Power Flow", International Journal of Control and Automation Vol.7, No.3 (2014), pp.161-176

*Corresponding author.

E-mail address: gklenin@ gmail.com 